\title{
PERMINTAAN TENAGA KERJA PEREMPUAN PADA INDUSTRI MIKRO DAN KECIL (IMK)
}

\begin{tabular}{|c|}
\hline Janiar Ningrum \\
Universitas Indonesia \\
janiar.ningrum@ ui.ac.id
\end{tabular}

Diterima: Oktober 2020; Disetujui: Maret 2021

\begin{abstract}
The Micro and Small Industry (IMK) contributes in creating employments in the informal sector. This study analyzes demand for female workers in the IMK sectors from 2016 to 2018 which is influenced by the number of establishments, outputs, and Provincial Minimum Wages. Fixed effect models in panel data has been carried out to analyze the data. It was found that the number of businesses and the output variable had a positive and significant relationship to the demand for female workers. The coefficient value of the number of businesses is 0.5743, which means that for every one percent increase in the number of IMK establishments the demand for female labor increased by 0.5743 percent. The coefficient value of the output is 0.2046 or for every one percent increase in output the demand for female labor increased by 0.2046 percent. Meanwhile, the UMP was found to be negatively and significantly related to the demand for female labor. The UMP coefficient value is 0.5642, which means that for every one percent increase in the UMP will reduce the demand for female labor by 0.5642 percent. The increase on number of establishments and outputs on IMK will have an impact on the female workforce.
\end{abstract}

Keyword: demand, labor minimum wage, output, panel data, small and micro industry.

Abstraksi. Industri Mikro dan Kecil (IMK) berperan menciptakan lapangan usaha di sektor informal. Penelitian ini menganalisis permintaan tenaga kerja perempuan di usaha IMK tahun 2016-2018 yang dipengaruhi oleh banyaknya usaha, output, dan Upah Minimum Provinsi (UMP). Metode estimasi fixed effect pada data panel telah dilakukan untuk menganalisis data. Berdasarkan hasil pengolahan ditemukan bahwa variabel banyaknya usaha dan output memiliki hubungan positif dan signifikan terhadap permintaan tenaga kerja perempuan. Nilai koefisien dari variabel banyaknya usaha sebesar 0,5743, yang berarti setiap kenaikan satu persen banyaknya usaha IMK akan meningkatkan permintaan tenaga kerja perempuan sebesar 0,5743 persen. Sedangkan nilai koefisien variabel output sebesar 0,2046, yang berarti setiap kenaikan satu persen output akan meningkatkan permintaan tenaga kerja perempuan sebesar 0,2046 persen. Sementara itu, variabel UMP yang ditemukan berhubungan negatif dan signifikan terhadap permintaan tenaga kerja perempuan. Nilai koefisien variabel UMP sebesar 0,5642, yang berarti setiap kenaikan satu persen UMP akan menurunkan permintaan tenaga kerja perempuan sebesar 0,5642 persen. Peningkatan banyaknya usaha dan output pada IMK akan berdampak terhadap tenaga kerja perempuan.

Kata kunci: data panel, industri mikro dan kecil, output, permintaan tenaga kerja, upah minimum.

\section{PENDAHULUAN}

Industri Mikro dan Kecil (IMK) memiliki share sebesar 3,6 persen terhadap Produk Domestik Bruto (PDB) di tahun 2018. Meskipun share IMK terhadap PDB lebih kecil dibandingkan Industri Besar dan Sedang (IBS) namun dalam beberapa kurun dekade terakhir usaha ini terbukti mampu bertahan menghadapi krisis keuangan tahun 1997-1998 dan krisis global tahun 2008- 
2009. Tambunan (2018) menyatakan bahwa industri mikro, kecil, dan sedang melakukan beberapa penyesuaian dalam menghadapi krisis untuk dapat mempertahankan profit dengan lebih berfokus kepada pasar domestik dan penyesuaian operasional jam kerja. Sifat dan karakteristik usaha yang fleksibel menyebabkan usaha tersebut mampu melakukan berbagai penyesuaian terhadap perubahan-perubahan yang terjadi secara tiba-tiba di dalam pasar. Penelitian Wiboonchutikula (2002) di Thailand juga menemukan bahwa usaha IMK mampu bertahan menghadapi kondisi sulit di saat pertumbuhan ekonomi berjalan lambat dengan menciptakan lapangan pekerjaan baru, yang pada kondisi tersebut tidak mampu diciptakan oleh perusahaan besar.

Usaha IMK juga berperan penting dalam penyerapan tenaga kerja di Indonesia. Badan Pusat Statistik (2019) mempublikasikan bahwa terdapat sebanyak 4.256.742 usaha IMK di Indonesia dan mampu menyerap tenaga kerja sebanyak 9.415 .858 orang. Dimana 93,72 persen diantaranya bekerja di Industri Mikro (usaha dengan tenaga kerja 14 orang), sedangkan sisanya bekerja di Industri Kecil (usaha dengan tenaga kerja 519 orang). Sementara itu, apabila dilihat menurut jenjang pendidikan terakhir yang ditamatkan, sebesar 74,78 persen pekerja IMK berpendidikan rendah (SMP ke bawah), dan hanya 25,22 persen yang berpendidikan tinggi.

Data diatas mengindikasikan peranan penting keberadaan usaha IMK dalam penyerapan tenaga kerja di Indonesia. Dalam keterkaitannya untuk menciptakan lapangan kerja, sifat usaha yang memanfaatkan sumber daya alam lokal, membutuhkan sedikit modal untuk mendirikan usaha, fleksibel, serta menghasilkan produk siap konsumsi untuk memenuhi kebutuhan pasar lokal, memungkinkan setiap orang dapat membuka usaha atau bekerja di sektor IMK. Termasuk kaum perempuan yang merangkap sebagai ibu rumah tangga dan mengandalkan usaha rumahan yang bersifat tradisional sebagai sumber mata pencaharian.

Penelitian terdahulu yang mempelajari tentang permintaan tenaga kerja telah banyak dilakukan. Nababan (2017) yang melakukan penelitian mengenai permintaan tenaga kerja pada usaha Industri Mikro menemukan bahwa jumlah usaha dan output berhubungan positif dan signifikan terhadap permintaan tenaga kerja. Sedangkan Upah Minimum Regional (UMR) berhubungan negatif dan signifikan terhadap permintaan tenaga kerja. Hasil temuan ini sejalan dengan Azizah et al. (2019), yang menemukan bahwa upah dan nilai produksi (output) berpengaruh terhadap permintaan tenaga kerja. Namun hasil temuan tersebut tidak sejalan dengan penelitian Prasetyo dan Huda (2019) yang menemukan bahwa upah tidak berbeda secara statistik dalam memengaruhi permintaan tenaga kerja.

Studi-studi yang telah dilakukan di Indonesia masih terbatas pada permintaan tenaga kerja usaha industri secara keseluruhan. Sedangkan studi empiris yang mengkaji tentang permintaan tenaga kerja perempuan di sektor IMK belum banyak dipelajari. Badan Pusat Statistik dalam publikasi hasil Survei Industri Kecil dan Mikro tahun 2018 melaporkan bahwa penyerapan tenaga kerja laki-laki lebih besar dibandingkan tenaga kerja perempuan. Tenaga kerja perempuan yang bekerja atau berusaha di usaha IMK sebanyak 4.403.713 tenaga kerja atau 46,76 persen dibandingkan total tenaga kerja IMK secara keseluruhan. Tenaga kerja merupakan faktor penting dalam proses produksi yang sering dianggap homogen, namun pada kenyataannya terdapat perbedaan secara jenis kelamin. 
Berdasarkan latar belakang tersebut, penelitian ini bertujuan untuk mengetahui pengaruh banyaknya usaha, output, dan UMP terhadap permintaan tenaga kerja perempuan pada usaha IMK di Indonesia.

\section{Usaha IMK di Indonesia}

Badan Pusat Statistik

(BPS)

mendefinisikan Industri manufaktur sebagai industri pengolahan yang mengubah barang mentah menjadi barang siap pakai atau barang setengah jadi, atau dari barang yang kurang nilainya menjadi barang yang lebih tinggi nilainya, termasuk ke dalamnya jasa industri atau maklun. Klasifikasi industri manufaktur yang digunakan merujuk pada klasifikasi jumlah tenaga kerja yang dipekerjakan. Usaha IMK didefinisikan sebagai industri manufaktur dengan jumlah tenaga kerja sebanyak 1-19 orang. Usaha IMK dapat dikategorikan lagi menjadi usaha dengan tenaga kerja 1-4 orang yang disebut industri mikro, sedangkan usaha dengan tenaga kerja 5-19 orang disebut sebagai industri kecil (BPSa, 2019).

Populasi usaha IMK pada tahun 2018 sebanyak 4,26 juta usaha dan tersebar di seluruh Indonesia. Sebesar 93,76 persen diantaranya merupakan industri mikro dan sisanya industri kecil. Berdasarkan hasil Survei Industri Mikro dan Kecil Tahunan tahun 2017 diperoleh informasi bahwa sebanyak 40,54 persen dari usaha mikro hanya memiliki tenaga kerja sebanyak satu orang dan 67,76 persen diantaranya adalah perempuan. Hal ini mengindikasikan bahwa ada sebagian perempuan yang terjun ke pasar tenaga kerja dengan mendirikan industri mikro, dimana mereka berperan sebagai pemilik sekaligus pekerja dalam menjalankan usahanya (BPSa, 2018).

Tambunan (2019) menyatakan 42,84 persen usaha IMK dimiliki oleh perempuan meskipun perbandingan antara pengusaha perempuan dan laki-laki bervariasi antar provinsi. Penelitian tersebut juga menemukan bahwa kemiskinan merupakan hal yang mendasari terus tumbuhnya usaha IMK. Perempuan yang memiliki usaha IMK terpaksa untuk menjalankan usaha agar dapat memperoleh uang tambahan untuk bertahan hidup. Hal ini sejalan dengan hasil penelitian Rodhiyah (2013) yang menyatakan bahwa perempuan yang bekerja di usaha UKM bertujuan untuk menambah penghasilan dan mencukupi kebutuhan sehari-hari keluarga. Perempuan juga masih mempunyai tanggung jawab pekerjaan rumah tangga, yang menyebabkan kurang produktif untuk memajukan usaha sehingga memperkecil pendapatan yang diperoleh dan membuat ketidakpastian kelangsungan UKM.

\section{Permintaan tenaga kerja}

Teori ekonomi menyatakan bahwa permintaan tenaga kerja merupakan turunan dari permintaan barang dan jasa. Dalam literatur ekonomi permintaan tenaga kerja diperlakukan sebagai model permintaan lainnya dengan ukuran tenaga kerja yang diminta sebagai variabel dependen dan satu set determinan penentu sebagai variabel independen (Bashier \& Wahban, 2013).

Permintaan tenaga kerja dipelajari dengan memahami fungsi produksi perusahaan dalam memproduksi barang dan jasa, yaitu seberapa banyak output yang dihasilkan menurut berbagai kombinasi tenaga kerja dan kapital. Faktor penting lainnya yang berhubungan dengan fungsi produksi perusahaan adalah produk marginal tenaga kerja $\left(\mathrm{MP}_{\mathrm{E}}\right)$ yang didefinisikan sebagai output yang dihasilkan dari mempekerjakan tambahan tenaga kerja dengan input lainnya diasumsikan konstan.

Dalam jangka pendek kapital pada perusahaan diasumsikan konstan. 
Perusahaan dapat memperkirakan output yang dihasilkan dari tenaga kerja dengan melihat kurva nilai marjinal produk. Kurva tersebut merupakan kurva permintaan tenaga kerja jangka pendek dan menunjukkan kenaikan pendapatan yang dihasilkan karena adanya penambahan tenaga kerja dengan asumsi modal tetap, dirumuskan sebagai berikut:

$\mathrm{VMP}_{\mathrm{E}}=\mathrm{p} \times \mathrm{MP}_{\mathrm{E}}$

Sedangkan nilai produk rata-rata yang dihasilkan pekerja dirumuskan sebagai berikut:

$\mathrm{VAP}_{\mathrm{E}}=\mathrm{p} \times \mathrm{AP}_{\mathrm{E}}$

$\mathrm{VMP}_{\mathrm{E}}$ merupakan nilai produk marginal tenaga kerja, $\mathrm{MP}_{\mathrm{E}}$ merupakan produk marginal tenaga kerja, $\mathrm{VAP}_{\mathrm{E}}$ merupakan nilai produk rata-rata tenaga kerja, $\mathrm{AP}_{\mathrm{E}}$ merupakan produk rata-rata tenaga kerja, sedangkan $\mathrm{p}$ merupakan harga.

Perusahaan yang memaksimalkan laba hanya mampu mempekerjakan pekerja sampai tingkat dimana nilai produk marjinal pekerja sama besar dengan tingkat upah. Pada suatu kondisi ketika tingkat upah turun, maka perusahaan dapat menambah jumlah tenaga kerja menjadi lebih banyak dan menggeser kurva permintaan tenaga kerja ke kanan. Dari gambar 1 terlihat awalnya upah di suatu perusahaan sebesar \$22 dan jumlah tenaga kerja yang dipekerjakan sebanyak 8 pekerja. Pada satu kasus dimana terjadi penurunan upah menjadi hanya $\$ 18$, maka perusahaan akan mampu mempekerjakan 9 pekerja.

Apabila peningkatan output diperoleh sebagai hasil dari perusahaan karena mempekerjakan lebih banyak pekerja, maka akan terjadi penurunan harga yang artinya nilai marginal produk menurun. Kurva permintaan tenaga kerja dalam jangka pendek atau nilai $\mathrm{VMP}_{\mathrm{E}}$ akan turun ke bawah dari 8 pekerja menjadi 9 pekerja. Sedangkan apabila harga output meningkat maka $\mathrm{VMP}_{\mathrm{E}}$ akan bergeser ke atas, dan lapangan pekerjaan yang dibuka menjadi lebih banyak yaitu dari 8 pekerja menjadi 12 pekerja (Borjas, 2016).

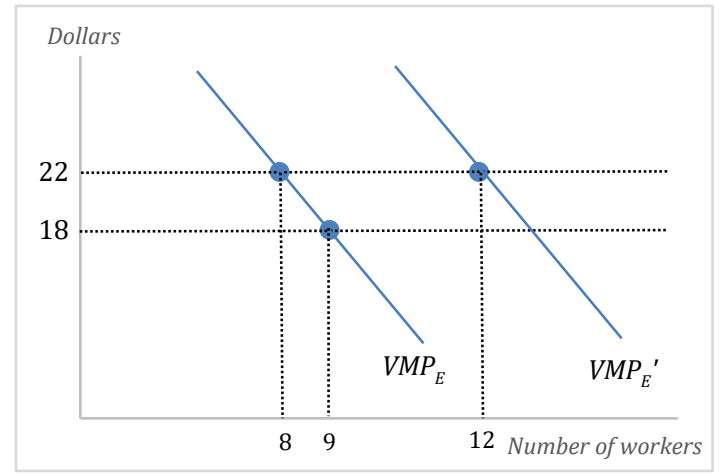

Gambar 1. Kurva permintaan tenaga kerja jangka pendek

Sumber: Borjas, 2016

\section{Studi Empiris}

Berbagai penelitian yang berkaitan dengan permintaan tenaga kerja pada IMK telah banyak dilakukan. Li \& Yama (2015) menemukan bahwa IMK menciptakan lapangan pekerjaan informal di negara berkembang. Demikian juga hasil penelitian Gebremeskel (2015) yang menemukan bahwa perusahaan IMK di Zambia menciptakan lapangan kerja dari waktu ke waktu. Namun terdapat gap antara jumlah pekerja laki-laki dan perempuan, dimana pekerja laki-laki hampir tiga kali lipat dari pekerja perempuan. Meskipun begitu, pertumbuhan tingkat pekerja perempuan hampir sama dengan pekerja laki-laki. Jumlah pekerja perempuan telah meningkat sebesar 3,76 persen sementara pekerja lakilaki meningkat sebesar 3,51 persen. Sejalan dengan penelitian tersebut, Olivetii \& Petrongolo (2014) menemukan adanya gap atau pemisah antara pekerja laki-laki dan perempuan di pasar kerja yang menyebabkan terdapat perbedaan jam kerja dan upah. 
Penelitian mengenai pengaruh jumlah usaha, nilai input, nilai output, nilai investasi, nilai modal, pengeluaran selain balas jasa pekerja, dan upah minimum kota maupun upah minimum regional telah banyak dilakukan (Saleh dan Kuncara, 1999; Sholeh, 2007; Putri, 2010; Setiawan, 2010; Rodhiyah, 2013; Nababan, 2017) dan ditemukan bahwa variabel-variabel tersebut berpengaruh terhadap permintaan tenaga kerja baik di UKM maupun industri mikro.

Sudarsono \& Setiaji (2004) menemukan bahwa terdapat hubungan negatif antara upah dan kesempatan kerja yang nilainya berfluktuasi. Penetapan UMP antar provinsi berbeda dan sangat variatif. Diferensiasi upah atau penetapan upah minimum sektoral di setiap provinsi memiliki signifikansi yang beragam dan cenderung mendiferensiasikan ke atas, dimana diferensiasi ke atas tersebut akan mengakibatkan perusahaan mengurangi penggunaan tenaga kerja.

Feriyanto (1997) menyatakan apabila ongkos produksi mengalami kenaikan maka daya saing perusahaan akan sangat merasakan efeknya karena kelompok UKM manajemennya belum efisien dan masih bergantung pada upah pekerja yang murah sebagai salah satu kekuatan daya saing produknya. Kenaikan Upah Minimum membuat beban usaha menjadi berat sehingga banyak pengusaha UKM yang tutup ketika kewajiban UMR harus dijalankan di tahun 1996. Saleh dan Kuncara (1999) menemukan bahwa kebijakan peningkatan UMR membuat pengurangan jumlah pekerja dimana 1,478 orang kehilangan pekerjaan mereka sehingga menurunkan kesejahteraan sosial.

\section{Kerangka Konseptual}

Banyaknya usaha, output, dan UMP memiliki pengaruh terhadap usaha IMK. Berdasarkan telaah literatur yang telah dilakukan maka dapat disusun kerangka konseptual yang akan digunakan pada penelitian seperti pada Gambar 2 ..

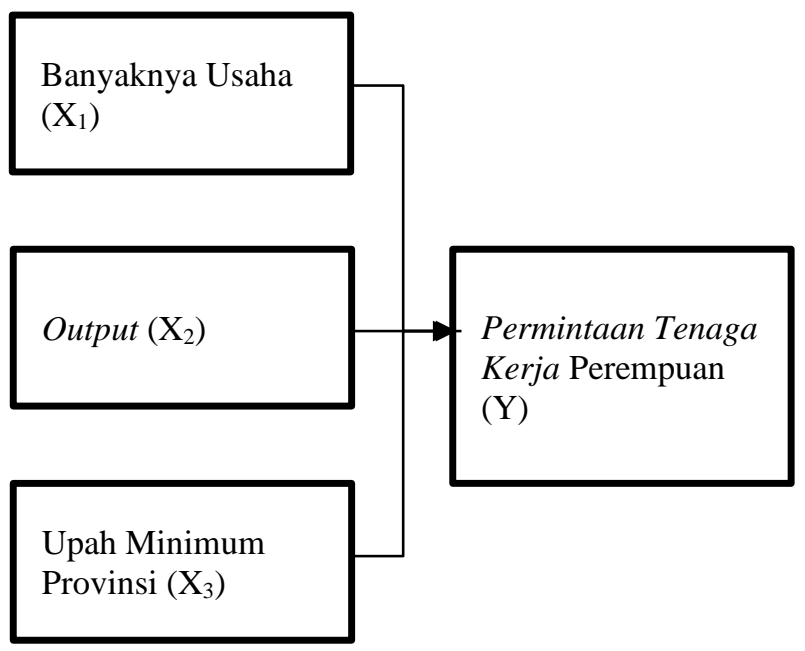

Gambar 2. Kerangka Konseptual Penelitian

Sumber: Borjas, 2016

Variabel permintaan tenaga kerja Sementara itu, variabel banyaknya usaha perempuan (Y) yang digunakan adalah $\left(\mathrm{X}_{1}\right)$ adalah jumlah unit usaha IMK yaitu banyaknya tenaga kerja perempuan yang industri pengolahan yang memiliki tenaga bekerja di usaha IMK dalam satuan orang. kerja antara 1-19 orang (acuan yang 
digunakan adalah konsep industri manufaktur dari Badan Pusat Statistik) yang diukur dalam satuan unit usaha. Variabel Output $\left(\mathrm{X}_{2}\right)$ yang dicakup pada penelitian ini adalah seluruh pendapatan yang dihasilkan usaha IMK meliputi nilai produksi barang/jasa, pendapatan dari jasa maklun, dan pendapatan lainnya yang masih berhubungan dengan kegiatan usaha dan diukur dalam satuan juta rupiah. Kemudian variabel UMP $\left(\mathrm{X}_{3}\right)$ merupakan upah minimum yang ditetapkan di masing-masing provinsi dengan yang diukur dalam satuan rupiah.

\section{METODE PENELITIAN \\ Data}

Penelitian ini menggunakan data sekunder berupa data panel yang meliputi data cross section dan time series. Data cross section bersumber dari hasil Sensus Ekonomi 2016 Lanjutan (SE2016-Lanjutan) dan Survei Industri Mikro dan Kecil Tahunan (VIMK tahunan 2017 dan 2018) dari publikasi yang diterbitkan Badan Pusat Statistik, serta data upah minimum dari publikasi Kementerian Ketenagakerjaan. Variabel yang digunakan meliputi banyaknya usaha IMK, output dan data UMP. Semua data cross section mencakup 34 provinsi di Indonesia. Sedangkan data time series yang digunakan adalah dari kurun tahun 2016-2018. Desain nama variabel yang digunakan dapat dilihat pada Tabel 1.

Tabel 1.

Definisi Operasional Variabel

\begin{tabular}{lcc}
\hline \multicolumn{1}{c}{ Nama Variabel } & Satuan & $\begin{array}{c}\text { Kode } \\
\text { Variabel }\end{array}$ \\
\hline Variabel Independen: & & \\
Permintaan Tenaga Kerja Perempuan $(\mathrm{Y})$ & & \\
Variabel dependen: & & \\
\hline Banyaknya Usaha $\left(\mathrm{X}_{1}\right)$ & Unit & BUP \\
Output $\left(\mathrm{X}_{2}\right)$ & Rupiah & OUTPUT \\
Upah Minimum Provinsi $\left(\mathrm{X}_{3}\right)$ & Rupiah & UMP \\
\hline
\end{tabular}

Sumber: SE2016, VIMK Tahunan (2017 dan 2018)

\section{Spesifikasi Model}

Model yang

digunakan untuk

mengestimasi variabel dependen dan variabel independen, dituliskan melalui persamaan berikut:

$$
\begin{aligned}
& \mathrm{LDP}_{\mathrm{it}}=f\left(\beta_{1} \mathrm{BUP}_{\mathrm{it}}, \beta_{2} \text { OUTPUT }_{\mathrm{it}},\right. \\
& \left.\beta_{3} \mathrm{UMP}_{\mathrm{it}}\right) \\
& \mathrm{LDP}_{\mathrm{it}}=\beta_{0}+\beta_{1} \mathrm{BUP}_{\mathrm{it}}+\beta_{2} \text { OUTPUT }_{\mathrm{it}}+ \\
& \beta_{3} \mathrm{UMP}_{\mathrm{it}}+\varepsilon_{\mathrm{it}}
\end{aligned}
$$

$$
\operatorname{LnLDP} \mathrm{Lit}_{\text {it }}=\operatorname{Ln} \beta_{0}+\beta_{1} \operatorname{LnBUP} \mathrm{Bu}_{\text {it }}+
$$$$
\beta_{2} \text { LnOUTPUT }_{\mathrm{it}}+\operatorname{LnUMP}_{\mathrm{it}}+\varepsilon_{\mathrm{it}}
$$

$L D P_{i t}$ merupakan permintaan tenaga kerja perempuan menurut provinsi dan tahun, $B U P_{i t}$ merupakan banyaknya usaha menurut provinsi dan tahun, OUTPUT $T_{i t}$ merupakan output usaha IMK menurut provinsi dan tahun, $U M P_{i t}$ merupakan Upah Minimum Provinsi menurut provinsi dan tahun, $L n L D P_{i t}$ merupakan bentuk logaritma natural dari $L D P_{i t}, L n \beta_{0}$ merupakan bentuk 
logaritma natural dari konstanta, LnBUPit merupakan bentuk logaritma natural dari $B U P_{i t}, \quad$ LnOUTPUT $_{i t}$ merupakan bentuk logaritma natural dari $O U T P U T_{i t}$, sedangkan ${ }_{L n U M P}{ }_{i t}$ merupakan bentuk logaritma natural dari $U M P_{i t}$.

$\beta_{0}$ merupakan konstanta, $\beta_{1}, \quad \beta_{2}, \beta_{3}$ merupakan koefisien dari regresi, $\varepsilon_{i t}$ merupakan eror term, $i$ merupakan observasi data cross section atau provinsi dimana $i=(11,12,13,14, \ldots ., i), \quad$ sedangkan $t$ merupakan waktu dari data time series dimana $t=(2016,2017,2018)$. Tanda yang diharapkan dari koefisien yaitu $\beta_{1}>0, \beta_{2}>$ 0 , dan $\beta_{3}<0$.

\section{Regresi data panel}

Model regresi data panel yang digunakan pada penelitian ini adalah analisis data panel dengan teknik analisis fixed effect dan random effect, selanjutnya dilakukan pengujian terhadap kedua model menggunakan Hausman Test untuk mendapatkan model permintaan tenaga kerja perempuan terbaik. Kemudian dilakukan pengecekan permasalahan heteroskedastisitas dan autokorelasi dan tahapan untuk mengatasi kedua permasalahan tersebut. Analisis elastisitas dalam persen perubahan digunakan untuk melihat perubahan permintaan tenaga kerja perempuan sebagai hasil dari perubahan variabel independen banyaknya usaha, output, dan UMP.

\section{HASIL DAN PEMBAHASAN Profil Usaha Industri Mikro dan Kecil}

Profil usaha IMK memberikan gambaran umum tentang industri pengolahan yang memiliki jumlah tenaga kerja 1-19 orang berserta dengan karakteristiknya. Usaha IMK merupakan industri padat karya yang lebih banyak menggunakan sumber daya lokal, memiliki keterbatasan sumber modal, dan masih menerapkan teknologi sederhana dalam menjalankan usaha sehingga sifat usaha ini mudah hidup tetapi juga mudah mati. Hal ini terlihat dari jumlah usaha IMK di Indonesia yang berfluktuatif dari kurun tahun 2016-2018 pada Gambar 3. Pada tahun 2016 sebanyak 4.383.622 usaha IMK berdiri kemudian meningkat menjadi 4.464.688 di tahun 2017, namun di tahun 2018 jumlah usaha turun menjadi 4.256.742 usaha.

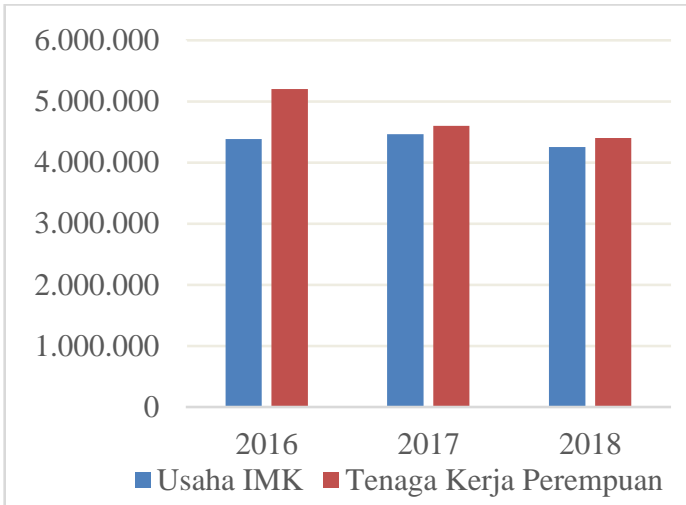

Gambar 3. Banyaknya Usaha dan Permintaan Tenaga Kerja Perempuan IMK Tahun 2016-2018

Sumber: SE2016 dan VIMK tahunan $(2017,2018)$, diolah

Usaha IMK merupakan sektor usaha yang mampu menciptakan lapangan pekerjaan (Gebremeskel, 2015; Li \& Yama, 2015). Berdasarkan karakteristiknya tenaga kerja yang bekerja di sektor ini mayoritas memiliki tingkat pendidikan terakhir yang ditamatkan kurang dari SMA/sederajat. Pada tahun 2018, usaha IMK mampu menyerap tenaga kerja perempuan sebanyak 4.402.038 orang.

Pada tahun 2016, output usaha IMK sebesar 671.685.101 juta rupiah mengalami penurunan sebesar 11,49 persen di tahun 2017 dan 12,04 persen di tahun 2018 pada Gambar 4. Hal ini dipengaruhi oleh menurunnya usaha IMK pada tahun yang sama sehingga terjadi penurunan output dengan pola yang sama. 


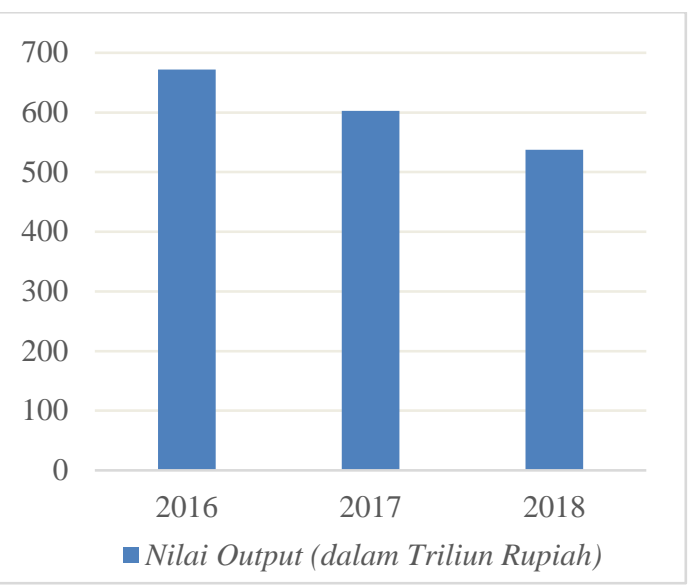

Gambar 4. Nilai Output Usaha IMK Tahun 2016-2018 (dalam Triliun Rupiah)

Sumber: SE2016 dan VIMK tahunan (2017, 2018), diolah.

\section{Hasil Output Regresi Data Panel}

Regresi data panel dengan teknik analisis fixed effect dan random effect telah dilakukan. Model ini diestimasi dalam bentuk regresi linier dan logaritma natural.

Hausman test telah digunakan untuk memilih model regresi data panel terbaik antara model fixed effect dan random effect. Berdasarkan output dari uji Hausman test diperoleh hasil bahwa model fixed effect merupakan model terbaik yang dapat digunakan pada penelitian. Sebagaimana yang dinyatakan oleh Wooldridge (2012) bahwa model fixed effect secara luas dianggap lebih meyakinkan untuk mengestimasi efek ceteris paribus dibandingkan model random effect.

Setelah mengatasi permasalahan heteroskedastisitas, hasil regresi data panel yang disajikan pada Tabel 2 menunjukkan bahwa model fixed effect untuk logaritma natural lebih baik dibandingkan model fixed effect untuk linier. Hal ini disebabkan karena semua koefisien (BUP, OUTPUT dan UMP) signifikan secara statistik dan tanda koefisien sesuai dengan harapan. Model regresi data panel terbaik untuk mengestimasi permintaan tenaga kerja perempuan pada usaha IMK, yaitu:

$L n L D P_{i t}=9,6547+0,5743 \operatorname{LnBUP}_{i t}+$ 0,2046 LnOUTPUT $_{i t}-0,5642$ LnUMP $_{i t}$

Nilai $\mathrm{R}^{2}=0,9964$ dan Prob (F-stat) $=0.000$ menunjukkan bahwa model sudah baik (well establish), dimana variabel banyaknya usaha, output dan UMP mampu menjelaskan 96,64\% variasi dari permintaan tenaga kerja perempuan. Variabel BUP memiliki pengaruh positif dan signifikan $(\alpha=0,01)$ terhadap LDP, OUTPUT memiliki pengaruh positif dan signifikan $(\alpha=0,05)$, dan UMP memiliki pengaruh negatif dan signifikan $(\alpha$ $=0,05$ ). Hasil ini sejalan dengan penelitian oleh Nababan (2017), yang menemukan bahwa model fixed effect dalam bentuk logaritma merupakan model terbaik dari analisis data panel yang dapat digunakan untuk mengestimasi variabel-variabel yang memengaruhi permintaan tenaga kerja. Selanjutnya Nababan (2017) menjelaskan bahwa model yang dibentuk menghasilkan nilai $\mathrm{R}^{2}$ yang besar, artinya model sudah dibentuk dengan baik, serta nilai dan tanda besaran koefisien variabel yang diperoleh sesuai dengan ekspektasi.

Tabel 2.

Estimasi regresi data panel

\begin{tabular}{lcccc}
\hline \multirow{2}{*}{ Variabel } & \multicolumn{2}{c}{ Coefficient (Linier) } & \multicolumn{2}{c}{ Coefficient (Logarithm Natural) } \\
& $\mathrm{FE}$ & $\mathrm{RE}$ & $\mathrm{FE}$ & $\mathrm{RE}$ \\
\hline \multirow{2}{*}{$B U P$} & 0,9466 & 1,0486 & 0,5743 & 0,7078 \\
& $(0,000)^{* * *}$ & $(0,000)^{* * *}$ & $(0,000)^{* * *}$ & $(0,000)^{* * *}$ \\
\hline
\end{tabular}




\begin{tabular}{lcccc}
\hline \multirow{2}{*}{ Variabel } & \multicolumn{2}{c}{ Coefficient (Linier) } & \multicolumn{2}{c}{ Coefficient } \\
& $\mathrm{FE}$ & $\mathrm{RE}$ & $\mathrm{FE}$ & $\mathrm{RE}$ \\
\hline \multirow{2}{*}{ OUTPUT } & 0,0007 & 0,0002 & 0,2046 & 0,2021 \\
& $(0,148)$ & $(0,393)$ & $(0,032)^{* *}$ & $(0,000)^{* * *}$ \\
UMP & $-0,0221$ & $-0,0219$ & $-0,5642$ & $-0,6531$ \\
& $(0,006)^{* * *}$ & $(0,001)^{* * *}$ & $(0,011)^{* *}$ & $(0,000)^{* * *}$ \\
konstanta & 47886,39 & 43561,57 & 9,6547 & 9,523 \\
\multirow{2}{*}{$\mathrm{R}^{2}$} & $(0,001)^{* * *}$ & $(0,009)^{* * *}$ & $(0,006)^{* * *}$ & $(0,000)^{* * *}$ \\
Prob (F-stat) & 0,9633 & 0.9674 & 0,9664 & 0,9679 \\
\hline
\end{tabular}

Jumlah Observasi $=99$
Variabel Dependen $:$ LDP
FE $=$ Fixed Effect dan RE $=$ Random Effect
$* * *)$ Sig. $1 \%, * *)$ sig. 5\%, and $*$ ) sig. 10\%
Sumber: SE2016, VIMK tahunan 2017, VIMK tahunan 2018, diolah.

\section{Interpretasi Regresi Data Panel}

Berdasarkan hasil regresi data panel yang diberikan pada persamaan 6, diperoleh informasi bahwa nilai koefisien dari variabel banyaknya usaha IMK yang dinotasikan sebagai BUP bernilai sebesar 0,5743. Artinya setiap kenaikan satu persen usaha IMK akan meningkatkan permintaan tenaga kerja perempuan sebesar 0,5743 persen. Banyaknya usaha IMK memiliki efek positif dan signifikan $(\alpha=0,01)$ terhadap permintaan tenaga kerja perempuan di Indonesia. Temuan ini sejalan dengan hasil studi yang dilakukan oleh Nababan (2017) dan Setiawan (2010) yang menemukan bahwa penambahan jumlah usaha memiliki efek positif terhadap permintaan tenaga kerja. Efek positif tersebut disebabkan oleh berbagai program kebijakan pemerintah yang bertujuan untuk mengembangkan usaha industri, seperti program subsidi input, pelatihan dan manajemen teknologi, inovasi usaha, serta bantuan pemantauan kualitas produk. Namun untuk mendapatkan efek yang lebih signifikan terhadap permintaan tenaga kerja, diperlukan kebijakan pemerintah yang berkelanjutan sehingga dapat diperoleh nilai koefisien di atas 1 (Nababan, 2017).

Banyaknya usaha IMK memiliki pengaruh paling kuat terhadap permintaan tenaga kerja perempuan. Semakin besar penambahan usaha IMK maka semakin besar pula penambahan tenaga kerja (Setiawan, 2010). Adanya pendirian usaha IMK akan membuka kesempatan kerja bagi pencari kerja perempuan sehingga jumlah tenaga kerja perempuan pada lapangan usaha ini akan meningkat. Namun di samping mendirikan usaha baru, diperlukan dukungan berkesinambungan dari pemerintah untuk mendorong usaha IMK agar terus berkembang sehingga dapat menyerap lebih banyak tenaga kerja Nababan (2017).

Variabel output usaha IMK yang dinotasikan sebagai OUTPUT memiliki nilai koefisien sebesar 0,2046. Artinya kenaikan setiap satu persen output IMK akan meningkatkan permintaan tenaga kerja perempuan sebesar 0,2046 persen. Koefisien dari variabel ini memiliki efek positif dan signifikan $(\alpha=0,05)$ terhadap permintaan tenaga kerja perempuan di Indonesia. 
Temuan ini sejalan dengan hasil penelitian Azizah et al (2019), Nababan (2017), dan Putri (2010).

Nababan (2017) menjelaskan bahwa output adalah nilai produksi secara keseluruhan yang akhirnya dijual kepada konsumen. Apabila permintaan produk meningkat maka penggunaan tenaga kerja akan ikut meningkat (Azizah et al., 2019). Sebagaimana Putri (2010) yang menjelaskan bahwa ketika output meningkat, industri membutuhkan lebih banyak input produksi, termasuk tenaga kerja, untuk menambah kapasitas produksinya.

Penambahan nilai output memperbesar kemampuan usaha IMK dalam menambah jumlah tenaga kerja perempuan. Nilai output menggambarkan besaran kapasitas produksi suatu usaha IMK. Semakin besar kapasitas produksi semakin besar juga kebutuhan akan tenaga kerja di suatu usaha, tanpa mengesampingkan kebutuhan akan faktorfaktor produksi yang lain seperti teknologi dan kualitas tenaga kerja. Temuan penelitian ini kontradiktif dengan hasil studi Setiawan (2010), yang menemukan bahwa output memiliki pengaruh positif tidak signifikan terhadap permintaan tenaga kerja. Selanjutnya dijelaskan bahwa meningkatnya nilai output dari UKM tidak berarti meningkatkan kebutuhan tenaga kerja karena adanya keterbatasan kapasitas produksi pada usaha. Tidak dapat dipungkiri bahwa selain tenaga kerja masih terdapat banyak faktor yang memengaruhi kapasitas produksi di samping perbaikan teknologi dan peningkatan kualitas tenaga kerja, seperti ketersediaan modal, jaringan pemasaran, kerja sama dalam pelatihan dan pendidikan yang dapat meningkatkan produktivitas tenaga kerja, peningkatan mutu produk, dan lain sebagainya.

Variabel Upah Minimum Provinsi yang dinotasikan sebagai UMP memiliki nilai koefisien sebesar negatif 0,5642. Artinya setiap kenaikan satu persen UMP akan menurunkan permintaan tenaga kerja perempuan sebesar 0,5642 persen. UMP memiliki efek negatif dan signifikan $(\alpha=$ 0,05) terhadap permintaan tenaga kerja perempuan di Indonesia. Temuan ini sejalan dengan hasil penelitian yang dilakukan oleh Setiawan (2010), Nababan (2017), dan Azizah et al (2019). Namun temuan ini tidak sejalan dengan Prasetyo dan Huda (2019) yang menemukan bahwa upah tidak signifikan memengaruhi permintaan tenaga kerja.

Nababan (2017) menjelaskan bahwa perusahaan hanya akan membayar upah sesuai dengan produktivitas tenaga kerja. Artinya, tenaga kerja dengan produktivitas rendah akan menerima upah rendah dan sebaliknya. Penetapan upah minimum lebih banyak ditentukan oleh aspek kenaikan tingkat harga dibandingkan dengan peningkatan produktivitas. Sehingga, produktivitas belum menjadi faktor utama dalam penentuan upah. Setiawan (2010) dalam studinya menjelaskan bahwa besaran upah memengaruhi tingkat keuntungan usaha. Ketika upah meningkat, pengusaha lebih memilih meningkatkan produktivitas pekerja yang sudah ada, atau mengurangi jumlah pekerja demi mempertahankan keuntungan yang diperoleh.

Azizah et al. (2019) menjelaskan bahwa tingkat upah yang meningkat akan memengaruhi kenaikan biaya produksi dan menyebabkan kenaikan harga. Ketika harga meningkat, permintaan barang akan berkurang sehingga usaha akan menurun tingkat produksi. Penurunan tingkat produksi inilah yang mengakibatkan berkurangnya permintaan terhadap tenaga kerja. Sedangkan Prasetyo dan Huda (2019) menjelaskan bahwa ketika upah meningkat maka industri lebih memilih untuk 
menggunakan alat produksi bertenaga mesin.

Koefisien UMP yang bernilai negatif telah sesuai dengan prediksi awal $\left(\beta_{3}<0\right)$. Dari sudut pandang pengusaha semakin tinggi UMP yang wajib dibayarkan kepada pekerja maka semakin besar biaya produksi atau kapital yang harus digunakan. Untuk menekan biaya produksi dan mempertahankan keuntungan maka usaha IMK tidak menambah pekerja dan berusaha meningkatkan produktivitas pekerja yang telah dimiliki untuk meningkatkan output. Jika pengusaha menganggap usaha mengalami kelebihan biaya balas jasa pekerja maka akan terjadi pemangkasan atau perampingan jumlah pekerja. Oleh sebab itu peningkatan UMP dapat menurunkan jumlah penyerapan tenaga kerja perempuan IMK.

\section{SIMPULAN}

Penelitian ini bertujuan untuk mengkaji hubungan antara variabel jumlah usaha, output, dan UMP terhadap permintaan tenaga kerja perempuan. Hasil estimasi dengan model fixed effect menunjukkan bahwa jumlah usaha memiliki hubungan positif dan signifikan terhadap permintaan tenaga kerja perempuan di usaha IMK. Output memiliki hubungan yang positif dan signifikan terhadap permintaan tenaga kerja perempuan di usaha IMK. Sementara itu, UMP memiliki hubungan negatif dan signifikan terhadap permintaan tenaga kerja perempuan di usaha IMK.

Industri Mikro dan Kecil berperan dalam menciptakan lapangan pekerjaan di Indonesia. Meningkatnya jumlah tenaga kerja di usaha IMK sama artinya dengan meningkatkan permintaan tenaga kerja perempuan. Demikian juga dengan output, meningkatnya output berarti bertambahnya kemampuan usaha IMK untuk meningkatkan permintaan tenaga kerja perempuan. Namun usaha IMK akan menghadapi kendala saat terjadi kenaikan UMP, yang dapat berimbas pada penurunan permintaan tenaga kerja akibat keterbatasan modal yang dimiliki usaha.

Meskipun penelitian mengenai permintaan tenaga kerja di usaha IMK sudah banyak dipelajari, namun penelitian yang khusus mempelajari tentang permintaan tenaga kerja perempuan masih sangat terbatas. Diharapkan penelitian selanjutnya dapat melakukan kajian lebih dalam, dengan memasukkan variabel-variabel yang mungkin dapat memengaruhi permintaan tenaga kerja, dan tidak hanya terbatas pada variabel utama yang melekat pada usaha IMK saja. Sehingga hasil studi tersebut dapat menambah ketersediaan studi empiris dan memperkaya khasanah ilmu pengetahuan yang berkaitan dengan topik ini di Indonesia.

Selain itu, pemerintah diharapkan dapat memberikan stimulasi secara berkesinambungan kepada IMK agar dapat menyerap lebih banyak tenaga kerja perempuan, serta diharapkan dapat melakukan peninjauan ulang terhadap ratarata Upah Minimum Provinsi yang disesuaikan dengan kebutuhan hidup di masing-masing wilayah. Selain itu, diharapkan pemerintah melalui dinas/instansi terkait yang memiliki kewenangan terhadap IMK dapat meningkatkan kualitas tenaga kerja perempuan. Dinas/instansi terkait dapat bekerja sendiri atau bekerja sama dengan instansi/lembaga/institusi tertentu untuk menyelenggarakan bimbingan, pelatihan atau penyuluhan (dapat berupa manajerial, teknik produksi, pengemasan, atau pemasaran produk) sehingga dapat membantu meningkatkan keterampilan tenaga kerja perempuan di sektor IMK, serta kelangsungan usaha IMK di Indonesia. 


\section{DAFTAR PUSTAKA}

Azizah, N., Purwaningsih, Y., dan Ratwianingsih, L. (2019). Analisis Faktor-faktor yang Memengaruhi Penyerapan Tenaga Kerja pada Industri Kreatif di Kota Surakarta. Prosiding Seminar Nasional: Fintech dan E-Commerce untuk Mendorong Pertumbuhan UMKM dan Industri Kreatif, Fakultas Ekonomi Universitas Tidar.

Badan Pusat Statistik (BPS)a. (2018). Profil Industri Mikro dan Kecil 2017. Jakarta: CV. Panji Anugrah Mandiri.

b. (2018). Hasil Pendataan Usaha/Perusahaan Industri Pengolahan Sensus Ekonomi 2016-Lanjutan Indonesial Result of Manufacturing Establisments Data Collection Economic Cencus 2016 Continued Indonesia. Jakarta: Badan Pusat Statistik.

a. (2019). Profil Industri Mikro dan Kecil 2018. Jakarta: Badan Pusat Statistik.

b. (2019). Keadaan Angkatan Kerja di Indonesia Agustus 2018/Labor Force Situation in Indonesia August 2018. Jakarta: PT. Kiel Putra Mandiri.

Borjas, G.J. (2016). Labor Economics Seventh Edition. New York: The MacGrow-Hill Companies.

Bashier, A., \& Wahban, N. (2013). The determinants of employment in Jordan: A time series analysis. International Review of Management and Business Research. 2(4).

Feriyanto, N. (1997). Upah Minimum Regional: Suatu Tinjauan. Jurnal Ekonomi \& Pendidikan. 2(2). 196-204.

Gebremeskel, Y. (2015). Job Creation and Employment-Gender-Gap among Micro and Small Enterprises. Business and Management Research. 4(2). http://dx.doi.org/10.5430/bmr.v4n2p1.

Li, Y., dan Rama, M. (2015). Firm Dynamics, Productivity Growth, and Job Creation in Developing Countries: The Role of Micro- and Small Enterprises. Oxford University Press on behalf of the International Bank for Reconstruction and Development. doi:10.1093/wbro/lkv002

Nababan, T.S. (2017). Effects of the Number of Industrial Enterprises, Values of Input and Output, and Regional Minimum Wage on Labor Demand in Indonesia: Empirical Study on Micro Industrial Enterprises. Review of Integrative Business and Economics Research. 6(4). 465-485.

Olivetti, C., dan Petrongolo, B. (2014). Gender Gaps Across Countries and Skills: Demand, supply and the industry structure. Review of Economic Dynamics. 17(4). 842-859. doi:10.1016/j.red.2014.03.001.

Putri, A.K. (2010). Analisa Permintaan Tenaga Kerja Industri Makanan, Minuman dan Tembakau di Indonesia. Jurnal Kajian Ekonomi. 9(1). https://ejournal.unsri.ac.id/index.php/jke/article/view/3114/0.

Putri, A.I. (2010). Employment Ansorbtion in Manufacturing Industry: Yogyakarta Case. Economic Journal of Emerging Markets. 2(2). 199-209.

Prasetyo, A. dan Huda, M. (2019). Analisis Peranan Usaha Kecil dan Menengah terhadap Penyerapan Tenaga Kerja di Kabupaten Kebumen. Jurnal Fokus Bisnis. 18(1). 26-35. 
Rodhiyah. (2013) Profil Tenaga Kerja Perempuan di Sektor Usaha Kecil Menengah (Studi Pada Tenaga Kerja Perempuan UKM Konveksi Di Kota Semarang). Jurnal Administrasi Bisnis. 2(1). 51-63.

Sholeh, M. (2007). Permintaan dan Penawaran Tenaga Kerja serta Upah: Teori serta Beberapa Potretnya di Indonesia. Jurnal Ekonomi \& Pendidikan. 4(1). 62-75.

Setiawan, A.H. (2010). Analisis Penyerapan Tenaga Kerja pada Sektor Usaha Kecil dan Menengah (UKM) di Kota Semarang. Jurnal Ekonomi dan Kebijakan, 3(1), 39-47.

Saleh, S., dan Kuncara, W. H. (1999). The Social Welfare Cost of the Regional Minimum Wage Increase Policy. Journal of Economic Perspective. 4(1). 92-101.

Setiaji, B. dan Sudarsono (2004). Pengaruh Differensiasi Upah antar Provinsi Terhadap Kesempatan Kerja. Jurnal Ekonomi Pembangunan. 9(2). 117-127.

Tambunan, T. T. H. (2018). The Impact of The Economic Crisis On Micro, Small, and Medium Enterprises and Their Crisis Mitigation Measures in Southeast Asia with Reference to Indonesia. Wiley Asia \& The Pacific Policy Studies. 1-21. doi.org/10.1002/app5.264.

Tambunan, T. (2019). Recent evidence of the development of micro, small and medium enterprises in Indonesia. Journal of Global Entrepreneurship Research. 9(18). 1-15. doi:10.1186/s40497-018-0140-4

Wooldridge, J.M. (2012). Introductory Econometrics A Modern Approach $5^{\text {th }}$ Edition. USA: South-Western Cengage Learning.

Wiboonchutikula, P. (2002). Small and Medium Enterprises in Thailand: Recent trends. Small Business Economics. 18(1). 213-226. 